\title{
Long-Term Hemodialysis and Nerve Conduction in Children
}

\author{
JAMES C. M. CHAN, AND GLORIA ENG \\ Nephrology Section, Department of Pediatrics, Medical College of Virginia, Division of Health Sciences, Virginia \\ Commonwealth University, Richmond, Virginia, USA; the Department of Physical Medicine, Children's Hospital \\ National Medical Center-George Washington University School of Medicine, Washington D. C., USA
}

\begin{abstract}
Summary
Initial observations in adults revealed that peripheral neuropathy, as documented by reduced conduction velocity is common :. chronic renal failure. Critical analysis of this problem in children on long-term dialysis is scarce, consisting of a single report which demonstrated that the motor nerve conduction velocities were decreased early and frequently with more severe depression in peroneal nerve velocities. This is in distinct contrast to data from adults, in whom uniform rates of deterioration are encountered. In addition, a direct correlation of the degree of nerve conduction defect with the severity of the renal failure is found in adult patients.

The present study showed a relative lack of nerve conduction defects in 11 children on long-term hemodialysis. With rare exceptions, the conduction velocities were normal. To date, no clinical symptoms of neuropathy were evident in our patients. It would seem that, with the short-dialysis schedule of 12-14 h/wk over a period of up to $5 \mathrm{yr}$, there is no progressive neuropathy as quantitated by nerve conduction measurements.
\end{abstract}

\section{Speculation}

Nutritional augmentation, treatment with 1,25-vitamin $D_{3}$, suppression of parathormone and other as yet undefined age-specific factors may be responsible for the prevention of peripheral neuropathy in these children, as compared to the high incidence in adults receiving similar dialysis treatment.

Polyneuropathy, in association with chronic renal failure, has long been recognized. However, this remains a medical oddity until hemodialysis prolongs the life of end-stage renal failure patients almost indefinitely, so that the debilities from neuropathies take on clinical significance in terms of full rehabilitation.

Initial observations in adults reveal that peripheral neuropathy, as documented by reduced conduction velocity is common in chronic renal failure. Critical analysis of this problem in children on long-term dialysis is scarce, consisting of a single report (14) and a subsequent systematic study (1), which demonstrated that the motor nerve conduction velocities are decreased early and frequently with more severe depression in peroneal nerve velocities. This is in distinct contrast to data from adults, in whom uniform rates for deterioration are encountered. In addition, a direct correlation of the degree of nerve conduction defect with the severity of the renal failure is found in adult patients.

Preliminary reports also indicate that long-term dialysis in children does not improve motor nerve conduction velocity and that peroneal velocity fails to recover 3 years after transplantation (1). These data are in distinct contrast to similar data in adult patients in whom dialysis (15) and transplantation (4) result in improvement in the uremic neuropathies.
The present study is undertaken to assess in greater detail the prevalence of these neuropathies in children on long-term dialysis for a mean of 24 months (4-60 months). Nerve conduction velocity has also been used to assess the adequacy of dialysis and the authors wish to use this measureable variable to monitor the longterm pediatric dialysis in our institution.

\section{MATERIALS AND METHODS}

Eleven patients with end-stage renal failure on long-term hemodialysis were followed with nerve conduction studies every 6 months over a followup period of up to 5 years. Their age, sex, primary diagnosis, and duration of renal disease before hemodialysis are summarized in Table 1 .

The indications for entering the program were irreversable endstage renal failure with uremic symptoms, uncontrollable by dietary and antihypertensive therapy. This usually coincided with serum creatinine persistently exceeding $10 \mathrm{mg} / \mathrm{dl}$. Each child received 4-6 hr dialysis treatment three times per week on parallel flow and/or coil disposable dialyzers. Silicone rubber-polytef arteriovenous cannula and arteriovenous fistula were used for vascular access. The dialysis procedures, delivery system, dietary and antihypertensive therapy were described in detail previously $(2,6,9)$. The dialysate calcium concentration was $6.0 \mathrm{mg} / \mathrm{dl}$; magnesium $1.2 \mathrm{mg} / \mathrm{dl}$; sodium $134 \mathrm{mEq} /$ liter; potassium $2.0 \mathrm{mEq}$ / liter; acetate $38 \mathrm{mEq} /$ liter; and chloride $100 \mathrm{mEq} / \mathrm{liter}$.

Predialysis (beginning of the week) blood for determinations of urea nitrogen, creatinine, hematocrit, $\mathrm{pH}$, total $\mathrm{CO}_{2}$, calcium, magnesium, and total protein were done every 2 to $4 \mathrm{wk}$, by standard methods previously described $(7,8)$. The averaged value of 10 determinations per patient was summarized in Table 2.

Nerve conduction was measured by a TECA Model B electromyograph. Supramaximal stimuli ( $150 \mathrm{~V}, 0.1 \mathrm{millisec})$ were given, and on occasion, duration of the stimulus was increased to $0.2-0.5$ msec, in order to obtain a response. Motor nerve conduction velocity of the right common peroneal, posterior tibial, the median and the sensory latencies of the median and sural nerves were serially recorded.

Control values for the motor conduction velocity were obtained for peroneal nerve in 67 normal children, median nerve in 38 , median sensory in 18 normal children, and previously published by Eng et al. (11).

\section{RESULTS}

The data on nerve conduction were summarized in Figure 1. The nerve conduction velocities in the lower extremities (common peroneal, posterior tibial, sural) were normal in all patients up to 24 months of hemodialysis. In one patient, the initial posterior tibial velocity was depressed during the lst year, but improved to the normal range in the 2 nd year of dialysis. The upper extremity's nerve conductions (median, median-sensory-latency) were normal up to 24 months of dialysis in all patients except one. 
Table 1. Clinical data of children receiving long-term maintenance hemodialysis

\begin{tabular}{|c|c|c|c|c|}
\hline Diagnosis & $\begin{array}{c}\text { Age at start of hemodialysis } \\
\text { mean yr (range) }\end{array}$ & $\begin{array}{c}\text { Known duration of renal } \\
\text { disease before dialysis } \\
\text { mean years (range) }\end{array}$ & Female & Male \\
\hline Focal glomerulosclerosis & $12(5-17)$ & $5(3-9)$ & 3 & 2 \\
\hline Obstructive uropathies & $12(9-14)$ & $6(4-8)$ & 1 & 1 \\
\hline Chronic glomerulonephritis & $10(8-11)$ & $4(1-7)$ & 1 & 1 \\
\hline Sickle cell nephropathy & 16 & 7 & 1 & \\
\hline Cystinosis & 8 & 8 & 1 & \\
\hline
\end{tabular}

Table 2. Mean values for blood constituents before dialysis

\begin{tabular}{|c|c|c|c|c|c|c|c|c|c|c|}
\hline & $\begin{array}{c}\text { BUN } \\
(\mathrm{mg} / \mathrm{dl})\end{array}$ & $\begin{array}{l}\text { Creatinine } \\
(\mathrm{mg} / \mathrm{dl})\end{array}$ & $\begin{array}{l}\text { Hct } \\
(\%)\end{array}$ & $\mathrm{Na}$ & $\begin{array}{c}\mathrm{K} \\
\text { (mEq/liter) }\end{array}$ & $\mathrm{tCO}_{2}$ & $\mathrm{Ca}$ & $\begin{array}{c}\mathrm{Mg} \\
(\mathrm{mg} / \mathrm{d})\end{array}$ & $\mathbf{P}$ & $\begin{array}{c}\text { Total } \\
\text { protein } \\
(\mathrm{gm} / \mathrm{dl})\end{array}$ \\
\hline \multicolumn{11}{|l|}{$n=11$} \\
\hline $\begin{array}{c}\text { Mean } \pm S D \text { of } 10 \text { val- } \\
\text { ues per patient }\end{array}$ & $103 \pm 27$ & $10.1 \pm 2.8$ & $14.6 \pm 3.0$ & $138.2 \pm 4.1$ & $4.8 \pm 1.7$ & $19.2 \pm 3.0$ & $9.4 \pm 1.2$ & $2.3 \pm 1.4$ & $5.5 \pm 2.7$ & $6.9 \pm 2.4$ \\
\hline
\end{tabular}
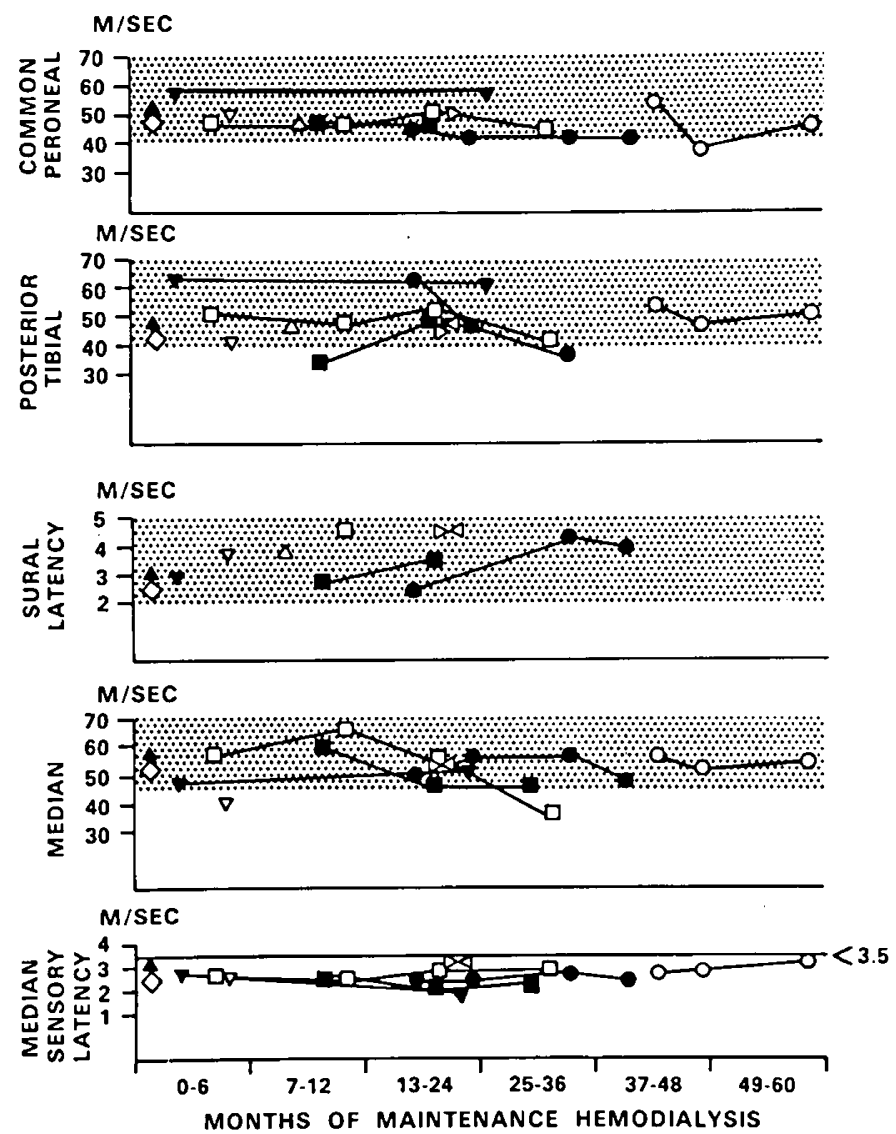

Fig. 1. Nerve conduction studies in 11 children over a period of up to 60 months of hemodialysis. The shaded areas are the 95 percentile confidence limits for normal subjects established in a previous report (11). Each symbol represent an individual patient.

Of the four patients dialyzed for periods exceeding 24 months, one showed deterioration of median nerve conduction by the end of the 36 months of dialysis, the other showed deterioration of posterior tibial conduction at 36 months. One patient was dialyzed for up to 60 months without deterioration of any of the parameters measured, even the somewhat depressed common peroneal nerve conduction at 48 months improved by the 60 th month of dialysis.

The mean values for blood constituents before dialysis were shown in Table 2: the blood urea nitrogen (BUN) and creatinine concentrations were elevated; the anemia and systemic metabolic acidosis were also shown. The relatively normal sodium, potassium, calcium, magnesium, phosphate, and total protein were also documented.

To date, no clinical symptom of neuropathy was evident in any of our patients.

\section{DISCUSSION}

In view of the observation that the severity of the motor neuropathy is in direct relationship to the duration of renal failure and that hemodialysis and transplantation reverse these defects in adult patients, it becomes important to document the presence and progression of neuropathy in hemodialyzed children. This question is of special significance in view of the recent report which tends to suggest that such neuropathy once developed in children is not reversable even after prolonged hemodialysis. To this end, we recorded the motor nerve conduction velocities at 6month intervals in all children entering (or transferred to) the dialysis program over a 5-year period.

The results of this study showed that in the first 24 months of maintenance hemodialysis, the risk of neuropathy occurred in 2 out of 11 children studied (18\%). This is lower than the $57 \%$ in 20 children similarly studied (1).

Of the four patients on dialysis exceeding 24 months, one showed deterioration of posterior tibial nerve conduction velocity (Fig. 1), with the others staying within normal ranges. Although in the one patient dialyzed for up to 60 months, there was improvement of nerve conduction velocity from a borderline value at 48 months. It is worthwhile to note this lack of deterioration for a duration of hemodialysis up to a period of 5 years.

The present data are also suggestive, at least in these two patients, that deterioration of nerve conduction may not be irreversable and indeed may improve. This finding is in conformity with results found in adult patients $(10,16)$, and is somewhat contrary to the previous observations in children (1).

It has been suggested that the "adequacy" of hemodialysis may be quantitated by measurable variables such as motor nerve conduction velocity, predialysis BUN, creatinine, and electrolytes (12). The predialysis biochemical data (Table 2) in these patients were no different from what was generally accepted for children on the three times per week schedule with 4-6 hr of dialysis each time. With reference to the question concerning what facet of patient care might have been responsible for the prevention of peripheral nerve disease in these children, one can only speculate on a few possibilites which are still under study: the role of trace mineral metabolism, the augmentation of nutritional intake (5), and the efficacy of different types of dialyzers.

In conclusion, it would seem that, with the short-dialysis schedule of $12-15 \mathrm{hr} / \mathrm{wk}$ over a period of up to 5 years, no progressive 
neuropathy was quantitated by conduction measurements. These data further support the contention that long-term hemodialysis is a viable treatment alternative in a situation where renal transplantation is of limited availability.

\section{REFERENCES AND NOTES}

1. Arbus, G. S., Barnor, N. A., Hsu, A. C., Murphy, E. G., Radde, I. C.: Effect of chronic renal failure, dialysis and transplantation on motor nerve conduction velocity in children. Can. Med. Assoc. Journal, 113: 517 (1975).

2. Beale, M. G., Salcedo, J. R., and Chan, J. C. M.: Management of hypertension in children on chronic hemodialysis and following renal transplantation. Clin. Proc. Child. Hosp. Nat. Med. Ctr., 30: 265 (1974).

3. Blagg, C. R., Kemble, F., Taverner, D.: Nerve conduction velocity in relationship to the severity of renal disease. Nephron, 5: 290 (1968).

4. Bolton, C. F., Baltzan, M. A., Baltzan, R. B.: Effects of renal transplantation on anemic neuropathy: a clinical and electrophysiologic study. N. Engl. J. Med., 284: 1170 (1971)

5. Chan, J. C. M.: Augmentation of nutritional intakes in children receiving longterm hemodialysis treatment. J. Urol., 118: 824 (1977).

6. Chan, J. C. M.: Dietary management of renal failure in infants and children: principle of nutritional therapy and some representative diets. Clin. Pediatr., 12: 707 (1973)

7. Chan, J. C. M.: The effect of milk formulae on acid balance. Nutr. Metab., 16: 140 (1974).
8. Chan, J. C. M., Grushkin, C. M., Malekzadeh, M., Better, O., and Fine R. N.: The adaptation of hydrogen ion excretion associated with nephron reduction in posttransplant patients. Pediatr. Res., 7: 712 (1973).

9. Chan, J. C. M. and Parrish, A. E.: Maintenance pediatric hemodialysis: principles and techniques. Clin. Proc. Child. Hosp. Nat. Med. Ctr., 30: 214 (1974).

10. Dyck, P. J., Johnson, W. J., Lambert, E. H.: Detection and evaluation of uremic peripheral neuropathy in patients on hemodialysis. Kidney Int., 7: S-201 (1975).

11. Eng, G. D., Hung, W., August, G. P., Smokvina, M. D.: Nerve conduction velocity determinations in juvenile diabetes: continuing study of 190 patients. Arch. Phys. Med. Rehabil., 57: 1 (1976).

12. Gotch, F. A.: Hemodialysis: technical and kinetic considerations. In: B. M. Brenner and F. C. Rector: The Kidney. Chap 41 (W. B. Saunders Co. Philadelphia, 1976).

13. Jebsen, R. H., Tenckhoff, H., Honet, J. C.: Natural history of uremic polyneuropathy and effects of dialysis. N. Engl. J. Med., 277: 327 (1967).

14. McVicar, M., Gauthier, B., Goodman, C. J.: Uremic neuropathy, monitoring of transketolase activity inhibition in a child. Am. J. Dis. Child., 125: 263 (1973).

15. Tenckhoff, H. A., Boen, F. S., Jebsen, R. H., Spigler, J. H.: Polyneuropathy in chronic renal insufficiency. J.A.M.A., 192: 1121 (1965).

16. Teschan, P. E., Ginn, H. E.: The nervous system. In: S. G. Massry, A. C. Seller: Clinical Aspects of Uremia and Dialysis. Chap. 1 (Charles C Thomas Publishers, Springfield, 1976).

17. Requests for reprints should be addressed to: James C. M. Chan, M.D., Box 822 , MCV Station, Richmond, VA 23298 (USA).

18. Received for publication October 31, 1977

19. Accepted for publication June 1, 1978. 